\title{
Social Class and Social Capital in China and Britain: A Comparative Study
}

\author{
Yaojun Li \\ Institute for Social Change, University of Manchester, Humanities Bridgeford Street, Oxford Road, Manchester, \\ M13 9PL, UK; E-Mail: Yaojun.Li@manchester.ac.uk; Tel.: +44 1612750274; Fax: +44 1612754762 \\ Submitted: 16 June 2013 | In revised form: 3 August 2013 | Accepted: 8 August 2013 | \\ Published: 16 August 2013
}

\begin{abstract}
We use the China General Social Survey (2005) and the Home Office Citizenship Survey (2005) to study civic engagement and neighbourhood trust in China and Britain in this paper. We focus on class differences in participation in sports/recreation, religion, children's/adult education and public-welfare activities, and trust in the neighbours. We find higher levels of civic involvement in Britain but greater neighbourhood trust in China. This is mainly due to structural differences. China has a large proportion of peasants who have very low levels of civic involvement but very high levels of neighbourhood trust. Among the non-peasant population, the two countries have similar levels of class differences in civic (except religious) involvement. There are small class differences in China on neighbourhood trust, but marked effects in Britain. Overall, there is a greater similarity than difference in class effects in both civic engagement and social trust in the two countries. While differences in demographic attributes (and China's specific institutional arrangement, the household registration system, or hukou) account for some of the observed patterns, we also find more pronounced class than demographic effects in the two countries. Class plays a major role in the development of social capital.
\end{abstract}

Keywords: Britain; China; civic engagement; class; hukou; neighbourhood trust

\section{Introduction}

Much research has been conducted on civic engagement and social trust, particularly in Britain and the USA. Yet, little is known about civic life and trust in China or how it is compared with that in developed countries such as Britain. This paper seeks to make a contribution to this respect. The two countries have different histories, socio-economic structures and political institutions impacting upon the two domains of social life. Britain has a long civic history but China's civic life is in its infancy. Even less known are the structural forces shaping civic engagement and social trust in the two countries. From a sociological perspective, we may expect both similarities and differences impinging upon the development of social capital. The similarity may be the common class determinant and the difference may be due to China's lack of civic tradition, its lower level of socio-economic development and its unique institutional arrangement 
(the household registration system, or hukou in Chinese) that can be expected to affect not only people's life chances such as social and geographic mobility but also life choices in civic involvement and social trust. Yet given the rapid economic development, the growing socio-economic disparity and the burgeoning civic life in China in the last three decades, a comparative study of the state and the drivers of social capital may be feasible, as is attempted in this paper.

This paper is structured as follows. In the next section, we give a brief review of the literature on social capital, paying particular attention to the civic tradition of the research paradigm. We also discuss some socio-political differences in the two countries that might have a strong bearing on the development of social capital. After that we give an account of the data and methods to be used for this research, followed by the presentation of results. The paper will conclude with a discussion of the implications of the findings.

\section{Debate on Social Capital}

There has been much debate on social capital in the last two decades. Scholars have argued about the nature and origin of social capital [1], the rise and fall of voluntary life in capitalist countries, particularly in the USA and Britain [2-5], the causes and consequences of voluntary involvement [6-8] and so on. Research on formal civic engagement in developing countries such as China is, however, limited although considerable research has been conducted on the instrumental aspects of informal social connections $[9,10]$.

Yet, in spite of the debate, a consensus is readily found about the nature of social capital in the writings not only by the well-known scholars in the area $[2,9,11,12]$ but also by those following a particular strand of the research paradigm. Briefly, most researchers in the area agree that social capital pertains to social resources residing in social connections. The disagreements are mainly on the manifestations and consequences associated with different kinds of social connection. Thus one finds striking similarities in the definitions of social capital: as 'the aggregate of the actual or potential resources which are linked to possession of a durable network of more or less institutionalised relationships of mutual acquaintance and recognition' ([11], p. 51); as 'resources embedded in one's network or associations' ([9], p. 56); as aspects of a social structure that facilitate 'certain actions of individuals who are within the structure' ([12], p. 302); and as 'connections among individuals-social networks and the norms of reciprocity and trustworthiness that arise from them' ([2], p. 19). It is fairly clear that Bourdieu, Coleman and Lin emphasize the stratification/instrumental functions of social connections whilst Putnam places greater importance to the expressive/civic values of formal and informal social involvement. We confine the following discussion on the civic tradition of this research paradigm.

In the civic tradition of social capital research, Putnam's work is the most influential. His notion of social capital is comprehensive and yet imprecise: comprehensive because it covers most of the research agenda in this area, and imprecise because it contains both causes (connection) and consequences (trustworthiness) in the same definition which has led to much controversy. He also views both connection and trust as consisting of different layers. With regard to connection, there are formal and informal social involvements. The former refers to membership and activity in civic organizations which are related neither with the state nor with employers (although some employers do have civic programmes in operation). This kind of civic activity has the function of community building and the participants in the voluntary activities are called 'machers' who are 'all-around good citizens' ([2], p. 94). In communities rife with volunteers, not only the machers but onlookers, passers-by and other members all benefit from the social cohesion, solidarity and generalized reciprocity that are engendered in the process. The cost of conducting socio-economic activity is reduced and the quality of life is enhanced. The latter, informal involvement, refers to the good-will and various acts of spontaneous and generous giving of time, effort and money to neighbours, friends, colleagues and others, fostering the flow of soul, or 'schmoozing' as Putnam calls it. Both formal and informal social networks facilitate the development of bonding and bridging ties, with the former referring to in-group solidarity and the latter to out-group linkage, which increase social interaction (although too much bonding might have a 'dark side' as Putnam also acknowledges), enhance mutual understanding, and strengthen community cohesion.

While there is general consensus about social capital inhering in social connections, there is less agreement about trust. We noticed that Putnam uses the term 'trustworthiness' rather than 'trust' as a defining characteristic of social capital, and warns of using 'trust' uncritically as an indicator. Unwarranted trust, he says, might simply mean 'gullibility' ([13], p. 668). Yet while his definition points to ego-based trust (one's own trustworthiness), his analysis is based on alter trust, that is, trust in fellow citizens ([2], pp. 139-141), a practice widely followed by most other researchers. The slippage is consequential for surveybased research. Trustworthiness refers, as he says, to the readiness to act in pursuance of the obligation of reciprocity but it is hard to validate this from survey responses. A person may be highly trustworthy in dealing with friends, colleagues and neighbours but acts cautiously or even unethically in dealing with strangers, or s/he may be utterly untrustworthy in personal behaviour but still proffers a trustful view in the response. One cannot therefore infer about a person's trustworthiness from survey responses. Yet, at a more general level, it may be fairly safely assumed 
that if a large proportion of people in a region or a country report that most people can be trusted, we can be quite confident about the general social atmosphere of that area in contrast to the situation in another place where most people regard one another with suspicion. Thus whilst an individual's credibility cannot be judged solely on the basis of his/her response to the survey item on generalised trust, aggregate responses in this regard do speak about the social character of a society.

More refined distinctions can be made with regard to alter trust: trust at the macro, meso and micro levels [14]. The first is the afore-mentioned trust in one's fellow citizens, which Putnam calls 'thin' trust to differentiate it from 'thick' trust in people with whom one deals in daily encounters, particularly among family and friends (micro-level trust). Putnam holds that thin trust 'rests implicitly on some background of shared social networks and expectations of reciprocity' and thick trust is 'embedded in personal relations that are strong, frequent, and nested in wider networks' ([2], p. 136). For decades, social and political scientists have relied on the survey question: 'Do you think that most people can be trusted or that you cannot be too careful?' Note here that the response modes to this question are set as mutually exclusive, but the question actually taps both attitudinal and behavioural aspects of trust. Being careful in dealing with strangers does not necessarily prevent one from forming a generally favourable judgement about the overall social milieu in which one finds oneself, while trusting fellow citizens does not presume carelessness in one's own behaviour [15]. Furthermore, neither response to this question says much about one's own trustworthiness as earlier noted. Thus, trust in fellow citizens, being careful in one's own activities and being trustworthy are different dimensions. On the other hand, a case could be, and indeed is often, made that information on generalised trust is valuable in aggregate analysis. A society with higher levels of generalised trust is usually one with better governance [16], less corruption and lower crime [17], higher economic growth [18] and better personal and public health [19]. Such associations are becoming more firmly established from findings based on large-scale datasets such as the European Social Survey or the World Value Survey.

An ongoing debate on the relationship between civic engagement and trust is concerned with which of the two has the causal priority. Putnam, following Tocqueville, holds that civic engagement is the 'school of democracy' where people learn from shared civic activities how to work together, solve collective problems, form a closer and more dynamic community and, in the process, become more trusting: 'those more engaged in community life are both more trusting and more trustworthy' ([2], p. 137). Yet it could also be the case that it is not civic activity that fosters trust but it is those who are innately trustful who are more likely to participate in civic activities in the first place. While analyses based on contemporaneous data cannot make causal inferences about trust from participatory activities, research using panel data can shed some light. For instance, using the British Household Panel Survey, Li, Pickles and Savage [20] show that, controlling for prior levels of trust, civic engagement does not make people more trusting. Similar findings are shown in Switzerland [21] and France [22], but not in Japan [23] which has fewer civic associations than other developed countries ([24], p. 501).

If civic engagement does not necessarily lead to greater trust, the question is turned to other possible sources. According to Uslaner [25], generalised trust is moralistic in nature, a value passed over generations and learned through early childhood. If one's grandparents or parents are more trusting, people will grow up with the world view that 'most people can be trusted'. This view also tallies with Putnam's observation that thin trust reflects one's life experience and with the survey findings that those from higher class origins, particularly the second-generation middle class, tend to display greater levels of generalised trust, in contrast chiefly with the second-generation working class ([26], p. 405; [27]). This may reflect the greater confidence of the most privileged groups in society in dealing with people in different situations, reinforced by their command of greater socio-economic-cultural resources and their safer working and living conditions protecting them from the harsh realities faced by the disadvantaged groups who may place greater trust in their bonding ties.

With regard to 'thick' trust at the micro level, that is, trust in one's family and friends, research shows that it has shrunk just as thin trust has much dissipated ([2], pp. 140-141). Pahl and Pevalin [28] and McPherson, Smith-Lovin and Brashears [29] show that people in the USA and in Britain have 'hunkered' in their social relations, with smaller circles of friends who are increasingly drawn from kin rather than from friends, colleagues or neighbours. The evidence on both strands of trust lends support to the thesis of declining social capital in the two countries.

Between thin and thick trusts, one may think of a meso-level trust, that is, trust in people in one's neighbourhood. Indeed, while thin trust in the generalized others (fellow citizens) may seem too nebulous to ordinary people and thick trust in family and friends could be generally taken as a given, the meso-level trust is regarded by some researchers as a better measure of community cohesion [30]. Most people's daily encounters are limited and they may have little knowledge about the trustworthiness of most, let alone all, of their fellow citizens, and their working life may be rife with competition. Trust in the neighbourhood could avoid these issues and it might also be seen as an indicator of one's own trustworthiness. People who trust most of their neighbours tend to have good relations with them through honest behaviour, generous help and frequent exchange of fa- 
vours, and are in turn accepted as being trustworthy by their neighbours. Untrustworthy people are unlikely to make friends or maintain good relations with neighbours. This kind of trust does not depend on one's socio-economic position as much as the macro level trust does. Given these and other considerations, one may argue, as do Heath and Laurence [30], that the meso-level trust is a better instrument than thin or thick trust for measuring social cohesion. In this paper, we adopt this approach and use neighbourhood trust together with civic engagement as the core elements of social capital in the two countries ([31], see [32-34]).

Having discussed civic engagement and social trust at some length, we now have a brief look at the socio-cultural underpinnings of social capital. Sociologists researching on social capital usually look at socio-economic differences in its generation. Here the general consensus is that formal civic engagement and generalised trust are conditional upon the socioeconomic resources at one's disposal. Take research on British social capital as an example. Although Hall [3] and Li, Savage and Pickles [4] disagree about the trends of social capital in the country, with the former claiming a vibrant and healthy civic life and the latter claiming a general decline, they do agree about the pronounced and increasing social division underlying the changes. As class-based research on China's civic engagement and social trust is limited, we know of no such analysis of Chinese civic life or trust (although see brief discussions in $[35,36])$.

A comparative study of civic life in Britain and China has considerable challenges. The two countries have many differences in terms of civic traditions, political institutions and levels of economic development. Britain has a democratic polity and a liberal economic system with a long tradition of civic engagement spanning over one hundred years [3,37]. Successive governments in Britain have adopted 'civicfriendly' policies. The current government is trying to build a 'Big Society' in order to 'mend the broken Britain' [38]. China's situation is rather different. With a state socialist polity and a dual economic structure (a growing market sector accounting for around $80 \%$ of the GDP but a strong state sector holding monopoly powers in key economic areas), civic engagement in China has rarely been officially endorsed or encouraged. Even in present-day China, the state grip on the voluntary sector is still firm, although much more relaxed than in the first three decades after the founding of the People's Republic of China in 1949. Furthermore, as Fei [39] observed long ago, China does not have a tradition of civic engagement, and Chinese social life is clan-based with a clearly-defined radius of trust extending, like a ripple, from family, kin, friends, neighbours, fellow-villagers/townspersons, fellow workers, to others.

A second difference relates to the shape of the class structure. Formal civic engagement is, as observed in previous research $[3,4,37]$, closely related to the state of economic and political life. Britain has a large middle class which has helped offset the civiceroding forces of the market. The decline in civic culture could, among other things, be traced to the marked changes in the occupational structure with the contraction of the working class and its involvement in trade unions and working-men's clubs. Middle-class civic participation tends to be spontaneous and individualistic. In the early 1970s when the British economy was in buoyancy, the working class enjoyed a healthy and vibrant civic life. Yet, with the state retrenchment, the collapse of heavy industry and the privatization of economic activity, the working-class collective strengths via trade unions have all but disappeared [40].

It is not possible to trace such trends in China, due to the lack of data. However, the rapid economic development in the last thirty years and the loosening of the ideological control by the state would lead us to expect a burgeoning civic life, especially in the urban areas where people may spontaneously organize themselves to solve problems engendered by the withdrawal of public services, the gnawing pains of economic transition, and the institutionally-backed inequality. For instance, during the economic restructuring, millions of urban workers, especially women, were laid off, many even in their thirties or forties. In search of a relatively meaningful and constructive life in the face of economic transition, growing competition and increasing inequality, many people would set up recreational, educational or mutual-help groups. Similarly, over 200 million peasants have moved into cities to find a job and better life for themselves and their children. How to spend their spare time and help with children's education is of chief importance to them.

We would also expect a growing civic life in China as a result of overall rising prosperity. From 1980 to 2005, the average real annual income in China increased at a rate 6.4 times as high as that of the world average ([41], p. 1489). Between 1970 and 2010, China's HDI (Human Development Indicator, developed by the United Nations Development Programme [42]) rose from 0.349 to 0.718 , ranking the country 75th place out of 135 countries with comparable data, above the regional average. Yet, with the rising prosperity comes increasing social inequality, with the Gini coefficient jumping from 0.35 in 1980 to 0.45 in recent years (some even estimated it to be over 0.5$)$, much higher than the 0.37 in the UK ([42], p. 26). In 2005, the per capita income in Shanghai (the richest place in China) was 7.6 times that in Guizhou (the poorest province in China). Boasting one of the most rapidly developing economies in the world, China is now finding itself with increasing unease and embarrassment (the overwhelming goal of the Chinese Communist Party and the Socialist system is to provide equality for the Chinese people, which is enshrined in the country's Constitution) as one of the most unequal 
and increasingly polarised societies. Within China, people of all walks of life and government at all levels are aware of the growing social inequality, and building a 'harmonious society' has become a state policy, with even the top leadership now calling for a 'scientific social management' [43] including a bigger role for the voluntary sector. More people with more money would also mean a more active civic milieu with a sizeable number among the growing middle and upper classes making contributions to voluntary, including fund-raising, activities to help the poor, fight against natural disasters, and enhance the public welfare in general.

Sociological analysis of social capital in China could hardly proceed without taking into account the most significant political institution, namely, the household registration system (hukou). This system, instituted in 1955 to regulate population migration, job assignment and resource allocation, has placed the rural and the urban sectors into the greatest social divide. A person's hukou status is determined at birth, following that of the mother. Most people in the countryside thus have rural hukou, and are destined to be peasants except for the few who could escape such a fate, usually via higher education or joining the army and becoming an officer. Although the system has been gradually loosened in recent years, particularly in small cities, access to urban hukou in big, particularly metropolitan, cities still remains an insurmountable barrier for most people born in the countryside. This system, absent in Britain, is not only an obstacle for social mobility, but also a hindrance for civic engagement: the two are closely linked. The institutionally-enforced lack of upward mobility chances, coupled with a clan-based and inward-looking tradition and culture, may produce an abundance of bonding ties but stifles formal voluntary activities.

There are many other differences between the two countries which cannot be covered here due to space limit. Yet one other difference has to be mentioned as it has a direct influence upon social capital generation. China is led by the Chinese Communist Party (CCP) with around 80 million members. As the predominant political force in the country with exclusive powers, the CCP members have more socio-economic resources than the population at large and are also expected to be 'vanguards' in political life and to serve as role models in socio-economic life. As civic engagement cannot be separated from the socio-political life in a country like China, any study of social capital would be incomplete without taking into account the role played by the CCP membership, just as with hukou. We shall therefore take both as China-specific factors in addition to the common socio-demographic factors in the analysis.

There are surely many other differences between the two countries which we do not have space to cover here. Even the factors outlined above-differences in civic tradition, socio-economic development and the unique combination of the CCP rule and the household registration (hukou) system in China, which is not only absent in Britain and other developed countries, but also in other countries of the developing world-would make the comparative study being undertaken here approximate to a 'most different systems' analysis which would lead us to expect pronounced differences in social capital in the two countries. Yet, from a sociological perspective, we may also expect some similarities, namely, that people in more advantaged social (class) positions in both countries would be more likely to find themselves in formal civic activities (and to benefit therefrom), and that there would not be much cross-country difference with regard to class effects. The questions we wish to address are therefore as follows: What are the shapes of civic engagement and neighbourhood trust in China and Britain? What are the common and the unique factors that explain the differences in the two respects? How big are the class differences relative to demographic/institutional ones?

\section{Data and Methods}

To address the questions outlined above, we use, in this study, the China General Social Survey (CGSS, 2005, hereafter called 'China') [44] and the Home Office Citizenship Survey for England and Wales (HOCS, 2005, hereafter called 'Britain' for ease of presentation although there is no intention that the findings will necessarily be applicable to Scotland) [45]. Both are large-scale national representative surveys. The CGSS is jointly conducted by the Survey Research Centre of the Hong Kong University of Science and Technology, and the Sociology Department of the People's University of China. The first CGSS survey was launched in 2003, followed annually or biannually. The CGSS covers 28 provinces, autonomous regions, and municipalities in mainland China with the exception of Qinghai, Tibet and Ningxia. The CGSS2005 has 10,372 respondents aged 18 years and over and resident in private households at time of interview. The HOCS is also a time-series data source conducted annually or biannually beginning in 2001. The HOCS2005 has 14,081 respondents aged 16 or over and resident in private households at time of survey. In the present paper, we confine the analysis to respondents aged 18 to 70 , resulting in a slightly reduced sample size for both surveys. Both datasets have cross-sectional weights (as provided by the data collectors) to account for selection biases, which are used in all analyses reported in the paper so that our findings can be generalized to the respective populations.

The most important reason for using the datasets is the availability of comparable questions on civic engagement and neighbourhood trust. In both data sources, the respondents are asked (CGSS2005 E18; CS2005 Fgroup) whether they partake in civic activities which are not sponsored by the state or organized by their employing organizations. Four common types 
of civic activity are selected for use in the analysis: sports/recreation, religion, children's/adult education, and public welfare (poverty relief, social justice, disaster aid and environment protection). The respondents are also asked (CGSS2005 E14b; CS2005 Strust) how many people in their neighbourhood could be trusted: many, some, a few, or none. As very few of the respondents say that they trust none of their neighbours (1.4\% in China and $1.6 \%$ in Britain), we have grouped the last two categories. These form our outcomes of interest (dependent variables) [46].

Both datasets have rich details on socio-demographic attributes. With regard to our main interest in the stratification factor, class, we use a modified Goldthorpe [47] class schema, differentiating the higher and the lower salariat (professionals, administrators and managers), routine non-manual, ownaccount, manual workers in industry and commerce, peasants [48] (for China) and never worked. Other variables included in the multivariate analysis are age, age squared, gender and marital status and, as mentioned above, China-specific factors on hukou and CCP membership [49]. As the central aim of the paper is to assess the class effects on the two domains of social capital in the two countries, it is essential that we assess whether class has stronger or weaker effects in Britain or China in each of the domains under discussion, and whether class effects are stronger or weaker than demographic/institutional ones in each country. For this purpose, we use the Wald test method [50].

\section{Analysis}

We now proceed with analysis. We start by looking at the sample characteristics and the overall profiles of civic engagement and neighbourhood trust in the two countries, and then move on to (gross and net) class effects on the two domains.

The data in Table 1 show that the two samples are basically similar in terms of age and gender distributions. Marital status is, however, much different, with around $87 \%$ of the Chinese sample but only $58 \%$ of the British sample being married [51]. In this regard, the Chinese people might be viewed as being much more 'traditional' than the British. Another salient difference concerns the distributions to class. As a developing country, China does not have as big a middle class as Britain. Only $10 \%$ of the Chinese are found in the salariat class, as compared with $35 \%$ in Britain. This is mainly due to a very large proportion of the Chinese ( $41 \%$ ) being peasants [52]. In terms of China-specific characteristics discussed earlier, we find $51 \%$ with rural hukou status and nearly $10 \%$ being CCP members.

Table 2 shows the overall profile of civic engagement and neighbourhood trust in the two countries. We list the proportions in each type of civic involvement in the upper, and those at each level of neighbourhood trust in the lower, panels. We also show whether the differences in the distributions in each category between the two countries are statistically significant, using China as the reference.

Table 1. Sample characteristics (percentages or means/standard deviations).

\begin{tabular}{lrc}
\hline & China & Britain \\
\hline Sex & & \\
$\quad$ Female & 53.2 & 50.4 \\
$\quad$ Male & 46.8 & 49.6 \\
Marital status & & \\
$\quad$ Non-married & 13.2 & 42.4 \\
$\quad$ Married & 86.8 & 57.6 \\
Class & & \\
$\quad$ Higher salariat & 4.8 & 10.8 \\
$\quad$ Lower salariat & 5.4 & 20.1 \\
$\quad$ Routine non-manual & 13.9 & 12.1 \\
$\quad$ Own account & 5.2 & 8.7 \\
$\quad$ Manual worker & 23.9 & 38.5 \\
$\quad$ Peasants & 40.9 & - \\
$\quad$ Never worked & 6.0 & 5.8 \\
Hukou origin & & \\
$\quad$ Urban & 48.6 & - \\
$\quad$ Rural & 51.4 & - \\
CCP member & 9.6 & - \\
Age (mean) & 42.8 & 42.6 \\
Age (SD) & $(13.0)$ & $(14.5)$ \\
(N) & 9,817 & 12,04 \\
\hline
\end{tabular}

Notes: 1. The urban/rural distinction and CCP membership status refer to China only; 2. For respondents resident in private households aged 18-70 at the time of interview; 3. Weighted analysis in this and all following tables. Sources: China General Social Survey (2005) [44] and Citizenship Survey (2005) [45]. 
Table 2. Proportions in civic engagement and neighbourhood trust in China and Britain.

\begin{tabular}{lrl}
\hline & China & Britain \\
\hline Participation in civic & & \\
organisations & & \\
$\quad$ Sports/recreation & 26 & $47^{* * *}$ \\
$\quad$ Religion & 6 & $17^{* * *}$ \\
$\quad$ Education & 24 & $32^{* *}$ \\
$\quad$ Public welfare & 23 & $33^{* * *}$ \\
Trust in neighbours & & \\
$\quad$ Many & 61 & $47^{* * *}$ \\
$\quad$ Some & 29 & $36^{* * *}$ \\
$\quad$ None/a few & 10 & $16^{* * *}$ \\
\hline
\end{tabular}

Note: Results of significance test for the difference in each category are shown with China as the reference category, ${ }^{*} p<0.05, * * p<0.01$ and $* * * \mathrm{p}<0.001$.

From the data in Table 2, we can see that the Chinese people are much less involved in civic activity but have much higher trust in their neighbours. In each of the four types of civic engagement, the Chinese sample has a significantly lower proportion than the British: around one half in sports/recreational and religious activities and two thirds in activities for children's/ adult education and for public welfare as compared with Britain. Yet a much higher proportion of the Chinese sample regards their neighbours as trustworthy: $61 \%$ of the Chinese as compared with $47 \%$ of the British say that many of their neighbours can be trusted [53].

The overall differences in the two domains are not hard to understand. China, as noted earlier, does not have a tradition of civic involvement. The Chinese culture encourages people to look up to the authorities for organizing socio-economic life and solving problems of social injustice. Yet, underlying these overall differences, there may be more powerful structural (class) differences. In the following analysis we try to disentangle such differences.

Table 3 shows the class differences in the four types of civic engagement. Apart from religion where the Chinese people are known to have a generally lower affiliation than the British, the distributions to the other aspects are as expected. Three notable features emerge from the table. First, the peasant class have a very low level of involvement in formal recre- ational, educational and public/welfare activities, much below any other group. Secondly, apart from this exceedingly low involvement as induced by the institutionally-enforced barrier, we also find marked class differences among the non-peasant sections in China, which amount to a similar extent to that found in Britain. Thus the differences between the higher salariat and the manual working class in sports/recreation in China run at 23 percentage points $(57 \%-$ $34 \%)$, comparable to the 24 point difference in the British sample in this regard $(61 \%-37 \%)$. The differences between the two classes are 19 and 14 points respectively in education, and 24 and 20 points respectively in public welfare. Thirdly, while there are fairly small class differences in religious involvement in China, such differences are still salient in Britain, with one in four of the higher salariat partaking in religious activities, twice as much as the manual working class.

Table 4 shows the data on neighbourhood trust. Here we find that those in the most disadvantaged positions in China, the peasants, are the most trustful group, with $71 \%$ saying that many people in their neighbourhood (village) can be trusted and only $6 \%$ believing that only a few or no one in their neighbourhood can be trusted. This is the most trustful class among all the Chinese social groups. Among the other classes in China, there is little difference in trust, with most groups having at least $50 \%$ believing that many of their neighbours can be trusted. The British profile is rather different, with those in more advantaged class positions being more trusting. Thus we find that $59 \%$ of the higher salariat but only $40 \%$ of the working class say that many of their neighbours can be trusted, with a difference of 19 percentage points in this regard.

While the data in Tables 3 and 4 show similar class effects in civic engagement between the two countries and greater class differentials in neighbourhood trust in Britain than in China, one might wonder whether such patterns are spurious. We noticed earlier that a much higher proportion of respondents in the Chinese sample were married and much research has shown that marriage is itself a form of social capital in multifaceted aspects $[2,7,20]$. So, perhaps the class differences as we have just observed are confounded and would reduce to insignificance once the demographic attributes such as age, gender and marital status as well as China-specific factors (hukou and CCP membership) are controlled for.

Table 3. Class differences in civic engagement in China and Britain.

\begin{tabular}{lcccccccc}
\hline & \multicolumn{2}{c}{ Sports/recreation } & \multicolumn{2}{c}{ Religion } & \multicolumn{2}{c}{ Education } & \multicolumn{2}{c}{ Welfare } \\
\cline { 2 - 9 } & China & Britain & China & Britain & China & Britain & China & Britain \\
\hline Higher salariat & 57 & 61 & 4 & 25 & 50 & 39 & 53 & 45 \\
Lower salariat & 56 & 57 & 6 & 23 & 48 & 41 & 48 & 45 \\
Routine non-manual & 43 & 51 & 8 & 19 & 39 & 36 & 36 & 35 \\
Own account & 20 & 46 & 8 & 18 & 27 & 31 & 23 & 29 \\
Manual worker & 34 & 37 & 6 & 12 & 31 & 25 & 29 & 25 \\
Peasants & 6 & - & 4 & - & 9 & - & 7 & - \\
Never worked & 42 & 32 & 10 & 16 & 30 & 26 & 25 & 20 \\
\hline
\end{tabular}


Table 4. Class differences in neighbourhood trust in China and Britain.

\begin{tabular}{lccrrrr}
\hline & \multicolumn{3}{c}{ China } & \multicolumn{3}{c}{ Britain } \\
\cline { 2 - 7 } & Many & Some & Few & Many & Some & Few \\
\hline Higher salariat & 58 & 31 & 12 & 59 & 34 & 7 \\
Lower salariat & 54 & 34 & 12 & 57 & 32 & 11 \\
Routine non-manual & 50 & 37 & 13 & 48 & 39 & 13 \\
Own account & 60 & 30 & 10 & 49 & 32 & 19 \\
Manual worker & 54 & 33 & 13 & 40 & 38 & 22 \\
Peasants & 71 & 23 & 6 & - & - & - \\
Never worked & 54 & 30 & 16 & 31 & 44 & 25 \\
\hline
\end{tabular}

To address this question, we conduct multivariate analysis. Table 5 shows logit regression coefficients where participation in each type of civic activity, and trusting 'many' neighbours [54] are our outcome variables. Apart from within-country analysis, betweencountry comparisons are also made with China as the reference.

Looking at the demographic attributes, we find that, controlling for all other factors in the models, Chinese men are significantly less likely to be involved in religious but more involved in children's or adult educational activities than Chinese women. The first finding may indicate greater time constraint and the second a conventional perception and associated sense of responsibility [55] that men should take a greater role in educational matters, especially children's education by, for instance, actively partaking in PTA matters. Except for greater participation in sports/recreation, British men are less likely to attend religious, educational and welfare activities than British women. With regard to cross-country comparison, we find, with the exception of sports/recreation which may indicate a relative lack of facilities in China, that British men play a smaller role than Chinese men in both education and public welfare activities. It is interesting to note that whilst no significant gender difference manifests itself with regard to neighbourhood trust in China, British men are found as being significantly more trusting than British women, attesting to previous research on US and UK societies with regard to generalized and particularized trust ([3], p. 432; [7], p. 71; [20], p. 118; [26], p. 405; [27], p. 35; although [7] p. 74 find notably but non-significantly higher male than female trust in neighbours). In Britain, marriage seems to have a more salient impact on civic activity than is found in China, which is unsurprising as an overwhelming majority of the Chinese sample are married. Nevertheless, in both countries, the married tend to have more congenial neighbourly relations as indicated by higher levels of neighbourhood trust. Other things being equal, age effects are generally slight in both countries.

The class effects manifest themselves most systematically and saliently. Controlling for all other variables in the models, we find the Chinese peasants being least likely to be engaged in civic activities, which is a clear indication of their lack of resources and opportun- ities. To this, we also need to add the significant inactiveness for people with rural hukou origins: people with the rural hukou origin status and currently found as peasants are doubly handicapped and their likelihood to engage in sports, education and welfare activities is very much behind that of their higher salariat compatriots $\left(\mathrm{e}^{(-1.71+-1.33)}=0.048, \mathrm{e}^{(-1.60+-0.94)}\right.$ $=0.079$, and $\mathrm{e}^{(-1.73+-0.88)}=0.074$ in the odds). People in non-salariat positions, particularly manual workers, are also found to be significantly behind their higher salariat counterparts in sports, education and welfare activities, and that in both countries. CCP members have, other things being equal, a generally more active profile in sports/recreation, education and public/welfare activities as well as in trust, which is most probably due to their greater command of socio-economic-cultural resources [56]. In Britain, the class gradients are salient and systematic, including those in neighbourhood trust, with the manual workers being only around one third to one half as likely as the higher salariat to engage in civic activities or to trust their neighbours (ranging from $\mathrm{e}^{-0.99}=0.37$ to $\mathrm{e}^{-0.69}=0.50$ in the odds).

Having looked at the data in some detail, we come to an overall look. Here we are interested in three questions as outlined earlier: (1) are there significant cross-country class differences for people in the same class positions? (2) in which of the two countries do we find greater class differences at the overall level? and (3) do class differences manifest themselves at a higher or lower level than demographic/institutional ones within each country?

As for the first question, our data in Table 5 clearly show that, apart from religion and trust where the Chinese people do not show much difference as earlier noted, there are few significant cross-country class differences. Only in 3 out of 12 tests (bold figures in the class part) do we find significant differences, and two of them are related to the self-employed: namely, that the own-account workers in China are even less likely than their British counterpart to engage in sports/recreational activities, or children's/adult educational clubs. This suggests that people in the same class positions in the two countries behave in a fairly similar way in terms of civic engagement. In other words, the relative advantages and disadvantages associated with class manifest themselves in basically the same manner in the two countries. 
Table 5. Logit regression coefficients on civic engagement and trust in neighbours ('trusting many') in China and Britain.

\begin{tabular}{|c|c|c|c|c|c|c|c|c|c|c|}
\hline & \multicolumn{8}{|c|}{ Civic engagement } & \multirow{2}{*}{\multicolumn{2}{|c|}{ Neighbourhood trust }} \\
\hline & \multicolumn{2}{|c|}{ Sports/recreation } & \multicolumn{2}{|c|}{ Religion } & \multicolumn{2}{|c|}{$\begin{array}{c}\text { Children/adult } \\
\text { education }\end{array}$} & \multicolumn{2}{|c|}{ Public welfare } & & \\
\hline & China & Britain & China & Britain & China & Britain & China & Britain & China & Britain \\
\hline Male (female $=$ ref) & 0.05 & $0.27 * * *$ & $-0.55 * * *$ & $-0.52 * * *$ & $0.14^{* *}$ & $-0.59 * * *$ & 0.08 & $-0.46 * * *$ & 0.04 & $0.20 * * *$ \\
\hline Age & $-0.10 * * *$ & $-0.03^{* *}$ & 0.04 & $-0.03 *$ & $0.03 *$ & $0.04 * * *$ & -0.02 & $0.02 *$ & 0.01 & 0.02 \\
\hline Age squared & $0.00 * * *$ & 0.00 & -0.00 & $0.00 *$ & $-0.00 * * *$ & $-0.00 * * *$ & -0.00 & -0.00 & -0.00 & 0.00 \\
\hline Married & $-0.35 * * *$ & 0.04 & -0.19 & $0.52 * * *$ & 0.00 & $\mathbf{0 . 5 4} * * *$ & -0.14 & 0.06 & $0.23 * *$ & $0.23 * * *$ \\
\hline \multicolumn{11}{|l|}{ Class $($ Higher salariat $=$ ref $)$} \\
\hline Lower salariat & -0.04 & -0.10 & 0.45 & $-0.22 * *$ & -0.15 & 0.02 & -0.17 & -0.11 & -0.10 & -0.02 \\
\hline Routine non-manual & $-0.47 * * *$ & $-0.33 * * *$ & $0.62 *$ & $-0.52 * * *$ & $-0.57 * * *$ & $-0.34 * * *$ & $-0.59 * * *$ & $-0.59 * * *$ & $-0.24 *$ & $-0.29 * * *$ \\
\hline Own account & $-1.24 * * *$ & $-0.56 * * *$ & $0.68^{*}$ & $-0.39 * * *$ & $-0.99 * * *$ & $-0.30 * * *$ & $-1.00 * * *$ & $-0.76 * * *$ & 0.04 & $-0.47 * * *$ \\
\hline Manual worker & $-0.66 * * *$ & $-0.98 * * *$ & 0.50 & $-0.98 * * *$ & $-0.78 * * *$ & $-0.69 * * *$ & $-0.75 * * *$ & $-0.99 * * *$ & -0.13 & $-0.69 * * *$ \\
\hline Peasants & $-1.71 * * *$ & & -0.33 & & $-1.60 * * *$ & & $-1.73 * * *$ & & 0.22 & \\
\hline Never worked & $-0.69 * * *$ & $-1.28 * * *$ & $0.78 * *$ & $-0.66 * * *$ & $-0.96 * * *$ & $-0.73 * * *$ & $-1.12 * * *$ & $-1.20 * * *$ & 0.01 & $-0.83 * * *$ \\
\hline Rural hukou (urban = ref) & $-1.33 * * *$ & & 0.12 & & $-0.94 * * *$ & & $-0.88 * * *$ & & $0.49 * * *$ & \\
\hline CCP member (other $=$ ref) & $0.51 * * *$ & & -0.29 & & $0.43 * * *$ & & $0.70 * * *$ & & $0.17^{*}$ & \\
\hline Constant & $2.95 * * *$ & $1.17 * * *$ & $-3.70 * * *$ & $-0.53 *$ & 0.34 & $-0.78 * * *$ & $0.83^{* *}$ & $-0.64 * *$ & -0.32 & $-0.88 * * *$ \\
\hline $\mathrm{N}$ & 9,624 & 11,781 & 9,624 & 11,781 & 9,624 & 11,781 & 9,624 & 11,781 & 9,534 & 11,77 \\
\hline
\end{tabular}

Notes: 1. For within-country differences in each domain, each category is contrasted with the reference category. ${ }^{\mathrm{p}} \mathrm{p}<0.05, * * \mathrm{p}<0.01, * * * \mathrm{p}<0.001 ; 2$. For between-country comparisons, significant differences in either direction are shown in bold under the column of Britain (all bold figures significant at the 0.05 level or higher). 
With regard to the second question, further analysis shows that there are no cross-country class differences at the overall level in terms of sports/recreational activities, children's/adult education and public welfare activities ( $p$ 0.817, 0.053, 0.993) but there are significantly greater class impacts in religion and trust in Britain than in China (at the 0.001 level) in both cases. This suggests that apart from religion, class operates in the same way in both countries in terms of civic engagement.

Finally in this section, further analysis with respect to the third question shows that class effects are significantly more pronounced than demographic (and including, in China, hukou and CCP membership) effects in each of the civic types and in neighbourhood trust, and that in both countries (all significant at the 0.05 level or above), attesting to the key role played by class in social capital development.

\section{Conclusions}

This analysis has focused on two domains of social capital in China and Britain: civic engagement and neighbourhood trust. Drawing on national representative surveys in the two countries containing similar questions on the two domains, our evidence shows stronger civic engagement in Britain but greater neighbourhood trust in China at the overall level. Yet underlying this are strong structural (class and, additionally in China, hukou) effects. In this section, we give some reflections on the findings.

With regard to the lower civic engagement in China than in Britain, there are of course many reasons. We have noted Fei's [39] famous discussion of China's tradition of clan-based social life under the centralised power system which, while fostering trust among family, friends, kin and neighbours, stifles civic spirit under which people spontaneously organize themselves to solve community problems, as was the case in the USA [2,57], and China also lacks the tradition of strong state support for civic associations as found in Britain $[3,37]$. The strict control by the Government since 1949 in almost every aspect of socio-economic life has also resulted in a rather unfavourable sociopolitical milieu for civic organizations to take root in China. It was during the reform period that NGOs, GONGOs (government-organized non-government organisations), or community groups such as literary groups, elderly groups, friendship groups, fellowstudent associations, sports/recreational clubs, religious and sundry hobby groups began to emerge and develop, which grew rapidly in the last one or two decades from 107,304 in 1991 to 386,917 in 2007 [58]. But civic organizations in general are finding themselves being sandwiched: they are being closely monitored by the Government and watched over by ordinary people with caution and even some suspicion [59].

The lower level of socio-economic development in China may also help to explain its lower civic engage- ment. As observed by many researchers $[2-4,7,20,26$, $30,33,34]$, the middle class has been the backbone of a vibrant civic life in the developed countries. As China's middle class is much smaller than that in Britain and as China has a very large peasant population, it may take decades for China to catch up. Yet our findings of a fairly similar role played by class in the two countries in civic engagement give the hope that as China's economy continues to grow and as its urbanisation programme strives forward, its civic life will begin to prosper too.

Our findings of the strong class effects on civic engagement also show the mounting challenges faced by the governments in the two countries in their attempts to build 'harmonious' or 'big' societies. Those in more privileged positions in China, just like their British counterparts, are more active in civic life whilst the manual working classes in both countries, particularly the peasants in China, face considerable shortages in socio-economic resources preventing them from taking an active part in civic activities. Although civic involvement has externalities, the main beneficiaries are the participants whose networks generate direct or indirect resources for themselves and their family. Privilege breeds privilege and many kinds of civic activity are arenas for developing bridging social ties serving both civic and instrumental purposes $[2,9,10]$.

Our analysis showed some apparently unusual features on religion and neighbourhood trust. As for religious engagement, the kind typically practised in rural China is folk religion such as ancestral tablets, memorial halls or Buddhist temples. In some urban and rural settings, Christianity has grown fairly rapidly in recent years, boasting more Christians in China than in Britain. Church activities are, however, not officially endorsed, may be shunned by the elites and are watched with suspicion by the authorities. Overall, formal religious activity is not a common practice. Religious involvement in Britain is much more formally organized where middle-class attendance is more prevalent than in China although a decline in both believing an belonging is also found in process $[26,60]$. The difference on trust is most probably due to the different mobility chances in the two countries. In Britain, owing to the high (absolute) rates of social mobility [61] and its attendant geographical mobility, the overall social homogeneity at the local level would be lower than that in China [62]. On the other hand, the presence of a long-existing housing market would mean that class clustering at the neighbourhood level would be higher than that in China. The greater social mixing may explain the class similarity in trust in China whilst the greater class clustering may explain the greater class differences in trust in Britain. Social mobility is a double-edged sword: it promotes economic development but disrupts social relations. As China's modernisation programme is bound to generate unprecedented levels of social and geographical mobility, 
how to maintain community cohesion is a challenge faced by the government and ordinary citizens.

Research on civic engagement and social trust tends to give the impression that the engaged and the trustful are heroes of a civil society. They are, in a certain sense. But their very ability to engage in civic life and to place trust in their fellow citizens resides in their greater command of socio-economic resources. The most disadvantaged, be they peasants or manual workers, are deprived of opportunities to engage in organized civic activities. It is these groups in whom the real hope of civic dynamics and social trust should be placed, for without their active engagement, no 'harmonious' or 'Big' society could be built. For that to happen, the rising socio-economic inequality must be curbed.

Finally, much research in the developed and the former socialist countries has shown the explanatory power of class in social mobility $[47,61]$ and educational attainment [63]. In this paper, we have shown similar class effects between Britain and China, and

\section{References}

1. Portes A. Social capital: Its origins and applications in modern sociology. Annual Review of Sociology. 1998;24:1-24.

2. Putnam R. Bowling alone: The collapse and revival of American community. New York, NY, USA: Simon \& Schuster; 2000.

3. Hall P. Social Capital in Britain. British Journal of Political Science. 1999;29(3):417-461.

4. Li Y, Savage M, Pickles A. Social Capital and Social Exclusion in England and Wales (1972-1999). British Journal of Sociology. 2003;54(4):497-526.

5. Grenier P, Wright K. Social capital in Britain: Exploring the Hall Paradox. Policy Studies. 2006;27(1): 27-53.

6. Sorensen E, Torfing J. Network Politics, Political Capital and Democracy. International Journal of Public Administration. 2003;26(6):609-634.

7. Sturgis $P$, Brunton-Smith I, Read S, Allum N. Does ethnic diversity erode trust? Putnam's 'hunkering-down' thesis reconsidered. British Journal of Political Science. 2010;41(1):57-82.

8. Castiglione D, Van Deth J, Wolleb G, editors. The Handbook of Social Capital. Oxford, UK: Oxford University Press; 2008.

9. Lin N. Social Capital. Cambridge, UK: Cambridge University Press; 2001.

10. Lin N, Erickson B, editors. Social Capital: An International Research Program. Oxford, UK: Oxford University Press; 2008.

11. Bourdieu P. Sociology in Question. London, UK: Sage; 1993.

12. Coleman JS. Foundations of Social Theory. Cambridge, MA, USA: Harvard University Press; 1990.

13. Putnam R. Commentary: 'Health by association': that in the social capital domain. The two countries possess as much difference as can be found almost in any other two countries in the world in terms of civic tradition, socio-economic development and political institutions. The similar class effects not only attest to the construct validity of class as a sociological concept but also the challenges faced by the governments in reducing the class inequalities.

\section{Acknowledgements}

I am grateful to the Economic and Social Research Council (ESRC) in Britain for funding the project 'Social mobility and social capital in China and Britain, a comparative study', (ES/I035168/1) which is linkfunded by the National Natural Science Foundation of China (NSFC) (71010090). Part of the analysis predated the project. I am very grateful to the three anonymous reviewers for their very helpful suggestions. I am alone responsible for any errors that may exist in the paper.

Some comments. International Journal of Epidemiology. 2004;33(4):667-671.

14. Halpern D. Social Capital. Cambridge, UK: Polity; 2005.

15. While most surveys use the classical question, the most recent one (the Great British Social Class survey conducted by the GfK in 2011) separates the elements. Two thirds of Britons (65.5\%) who agree that 'most people can be trusted' also agree to the statement that 'you cannot be too careful'.

16. Newton K. Social Capital and Democracy. American Behavioural Scientist. 1997;40(5):575-586.

17. Halpern D. Moral values, social trust and inequality-Can values explain crime? British Journal of Criminology. 2001;41(2):236-251.

18. Roth F. Does too much trust hamper economic growth? Kyklos. 2009;62(1):103-128.

19. Wilkinson R. Unhealthy Societies: The Afflictions of Inequality. London, UK: Routledge; 1996.

20. Li Y, Pickles A, Savage M. Social Capital and Social Trust in Britain. European Sociological Review. 2005;21(2):109-123.

21. Frietag M. Beyond Tocqueville: The origins of social capital in Switzerland. European Sociological Review. 2003;19(2):217-232.

22. Mayer N. Democracy in France: Do associations matter? In: Stolle D, Hooghe M, editors. Generating Social Capital: Civil Society and Institutions in Comparative Perspective. New York, NY, USA: Palgrave Macmillan; 2003. pp. 43-66.

23. Freitag M. Social Capital in dissimilar democracies-The development of generalised trust in Japan and Switzerland. Comparative Political Studies. 2003; 36(8):936-966.

24. Kerbo $H$. Social Stratification and Inequality, 5th ed. New York, NY, USA: McGraw Hill; 2003. 
25. Uslaner E. The Moral Foundations of Trust. Cambridge, UK: Cambridge University Press, 2002.

26. Li Y, Savage M, Warde A. Social mobility and social capital in contemporary Britain. British Journal of Sociology. 2008;59(3):391-411.

27. Welch M, Sikkink D, Loveland $M$. The Radius of Trust: Religion, Embeddedness and Trust in Strangers. Social Forces. 2007;86(1):23-46.

28. Pahl R, Pevalin D. Between family and friends: A longitudinal study of friendship choices. British Journal of Sociology. 2005;56(3):433-450.

29. McPherson M, Smith-Lovin L, Brashears M. Social isolation in America: Changes in core discussion networks over two decades. American Sociological Review. 2006;71(3):353-375.

30. Heath A, Lawrence J. Predictors of community cohesion: Multilevel modelling of the 2005 Citizenship Survey. 2008. Available from: http://www.communities. gov.uk/documents/communities/pdf/681539 (accessed on 22 March 2008). See also: Lawrence J. The Effect of Ethnic Diversity and Community Disadvantage on Social Cohesion: A Multi-Level Analysis of Social Capital and Interethnic Relations in UK Communities. European Sociological Review. 2009;1(1):1-20.

31. Other aspects of civic engagement and trust can be differentiated such as politically-oriented associations and trust in political institutions ([32,33,34]).

32. Paxton P. Is Social Capital Declining in the United States? A Multiple Indicator Assessment. American Journal of Sociology. 1999;105(1):88-127.

33. Li Y, Marsh D. New forms of political participation: Searching for Expert Citizens and Everyday Makers. British Journal of Political Sciences. 2008;38(2): 247-272.

34. Li Y. Measuring social capital: Formal and informal activism, its socio-demographic determinants and socio-political impacts. In: Bulmer M, Gibbs J, Hyman $L$, editors. Social measurement through social surveys: an applied approach. Aldershot, UK: Ashgate Publishing; 2010. pp. 173-194.

35. Fukayama F. Trust. New York, NY, USA: Free Press; 1995.

36. Paxton P. Association Memberships and Generalized Trust: A Model of Generalized Trust in ThirtyOne Countries. Social Forces. 2007;86(1):47-76.

37. Szreter S. The state of social capital: Bringing back in power, politics and history. Theory and Society. 2002;31(5):573-621.

38. Cameron D. We must mend our broken society. The Guardian; 11 August 2011.

39. Fei X. Xiangtu Zhongguo. Beijing, China: Sanlian Shudian; 1947. English translation by: Hamilton G, Zheng W. From the Soil: The Foundations of Chinese Society. Berkeley, CA, USA: University of California Press; 1992.

40. An analysis of the trends can help make this point clearer. The Social Mobility Inquiry survey conducted in 1972 shows that 40\% of men aged 20-64 in that year were union members and the proportion for those in the working class was at a much higher level: 52\%. In the Home Office Citizenship Survey of 2010 we find that, for men of the corresponding ages, the figures are only $10 \%$ and $9 \%$ respectively.

41. Hung $\mathrm{H}$, Kucinskas J. Globalization and Global Inequality: Assessing the Impact of the Rise of China and India, 1980-2005. American Journal of Sociology. 2011;116(5):1478-1513.

42. UNDP. Regional Report on Human Development; 2010. Available from: http://hdr.undp.org/en (accessed on 10 September 2012).

43. Hu J. Take real steps in enhancing scientific social management. People's Daily; 19 February 2011.

44. China General Social Survey. Available from: http://www.cssod.org/search.php?key=CGSS (accessed on 7 March 2008).

45. Home Office Citizenship Survey. Available from: http://www.data-archive.ac.uk/findingData/hocsTitles.a sp (accessed on 12 September 2007).

46. The question wording to these outcome variables in the two surveys are rather long and we do not reproduce them here. Interested readers could follow the links in Notes 44 and 45.

47. Goldthorpe J. Social Mobility and Class Structure in Modern Britain. Oxford, UK: Clarendon Press; 1987.

48. Class is indexed by the respondent's current (and for those currently not in gainful employment, last main) job in both countries as is the standard practice in class analysis. Around a quarter of people with rural hukou origins in our Chinese sample were doing non-agricultural work and are coded according to the jobs they were doing. It is also noted here that some people residing in suburban areas and doing agricultural work are given urban hukou. Residence and hukou are not equivalent in China. Over two hundred million peasants are living and working in cities as 'migrant workers', who retain their origin hukou status. Manual workers in Classes V-VII in the Goldthorpe class are hard to differentiate in China and are thus grouped together for both countries. As only $0.39 \%$ and $0.48 \%$ of the working-age population in Britain were found in Classes IVc and VIIb respectively in the Goldthorpe class schema (farmers and small holders, and agricultural labourers), it is not possible to code a farming class in the British data for comparative analysis with China's peasant class.

49. We do not include education in the analysis. This is because class destination in China depends primarily upon hukou. Only a very small proportion of people with rural hukou origin status could have tertiary education. The overwhelming majority, even those with higher secondary education, would have to stay in the countryside. The institutional barriers thus mean that educational effects between the urban and the rural sectors are incomparable and to introduce them to the comparative analysis is likely to bring bias. (We conducted analysis including education and that for the urban and the rural hukou origins separ- 
ately. The overall class patterns are similar to those reported in the text. The results are available on request). We also conducted analyses including employment status in addition to all the other variables in the modelling exercises. Unemployment has little effect on civic engagement in Britain but negative effects in China (with the exception of religion). The unemployed in both countries are less trusting, more so in Britain than in China. However, including employment status does not change the main patterns on class. As the main focus in this paper is on class, we do not present the analysis on employment status (available on request).

50. The formula for the test is written as $t=(b 1-$ b2) $/\left(s 1^{2}+s 2^{2}\right)^{1 / 2}$. The tests are conducted using the seemingly unrelated estimation method (suest in Stata).

51. Further analysis, not shown in the table, reveals that over half of the Chinese sample aged 24 and 25 were married, reaching $70 \%-80 \%$ between ages $26-29$ and over $90 \%$ for people aged 30 or over but in none of the similarly coded age groups in the British sample do we find over $70 \%$ of the respondents being married.

52. Among the urban sample in China, the salariat was much larger, at $18 \%$, and the proportion of the working class (38\%) was almost the same as that in Britain (39\%).

53. Further analysis shows that apart from religion, the urban sample in China had similar civic engagement to the British: $45 \%, 38 \%$ and $36 \%$ in sports, education and public welfare. The rural sample had much lower involvement: $9 \%, 11 \%$ and $10 \%$ respectively.

54. We also conducted an ordinal logit model on neighbourhood trust. The patterns including the Wald test results are similar to those reported here (data available upon request).

55. This may reflect the influence of Confucianism which, for thousands of years, has taught us that men in general, and intellectuals in particular, should take it as their duty to 'nurture the mind, cultivate the body, support the family, provide good governance to the country and bring peace to the world' (zhengxin, xiushen, qijia, zhiguo, pingtianxia, from Confucius: The Great Learning).

56. We also carried out an analysis excluding hukou and CCP membership which shows basically similar patterns but with some slight changes in the cross-country comparisons (data available upon request).

57. Tocqueville A. Democracy in America. New York, NY, USA: W.W. Norton \& Company; 2007.

58. Chan K. Civil Society and Social Capital in China. Democracy. 2009;16(3):5-19.

59. NGOs in China have to register with the Government or become 'patronised' (affiliated to government units, state enterprises or public organisations such as universities) and are thereby directly or indirectly controlled. Although many NGOs have made significant contributions to poverty alleviation, children's education in rural and especially mountainous areas, environmental protection and public health, some of them are notoriously corrupt, turning away many volunteers and potential donors as witnessed in the very low levels of donations to the earthquake victims earlier this year (2003) as compared with the profuse enthusiasm and very generous donations a few years ago in a similar natural disaster. Given the already very weak basis of civic engagement in China, the corruption scandals add salt to the wound. This also shows the challenges faced by the nascent civic organisations in China.

60. Voas D, Crockett A. Religion in Britain: Neither Believing nor Belonging. Sociology. 2005;39(1):11-28.

61. Goldthorpe JH, Mills C. Trends in intergenerational class mobility in Modern Britain: Evidence from national surveys. National Institute Economic Review. 2008;205(1):83-100. See also: Li Y, Devine F. Is Social Mobility Really Declining? Intergenerational Class Mobility in Britain in the 1990s and the 2000s. Sociological Research Online; 2011. Available from: http://www.soc resonline.org.uk/16/3/4.html (accessed on 3 September 2011).

62. Further analysis using the HOCS2005 shows that $60 \%$ of higher salariat households in Britain live in wealthy and prosperous areas as compared with only $17 \%$ of those headed by routine manual workers. No data on neighbourhood deprivation are available in CGSS2005.

63. Breen R, Luijkx R, Müller W, Pollak R. Non-Persistent Inequality in Educational Attainment: Evidence from Eight European Countries. American Journal of Sociology. 2009;114(5):1475-1521. 